\title{
Comparison of Students' Perceived Learning in Two Similar Lab Courses with Different Teaching Staffs
}

\author{
Ingrid N. Haugen ${ }^{1, *}$, Eirik Sundby ${ }^{2}$ \\ ${ }^{1}$ Department of Chemistry, Norwegian University of Science and Technology (NTNU), Norway \\ ${ }^{2}$ Department of Materials Science and Engineering, Norwegian University of Science and Technology (NTNU), Norway
}

Received February 7, 2020; Revised March 31, 2020; Accepted May 13, 2020

Copyright $\odot 2020$ by authors, all rights reserved. Authors agree that this article remains permanently open access under the terms of the Creative Commons Attribution License 4.0 International License

\begin{abstract}
At the Norwegian University of Science and Technology (NTN), two subjects with similar chemistry laboratory exercises have different practices with respect to the use of permanent and temporary staffs. In an ever-increasing focus on costs related to this type of teaching, we have investigated this difference and examined the students' perceived learning outcomes in two similar courses with different teaching practices. The results show that the students in both courses find the lab exercises relevant to the subjects and that they receive good guidance during the practical work. The most important findings reported by the students are related to the feedback students receive on their reports and most importantly how they choose to use this feedback. The students in the lab courses with permanent employees seem to use feedback more actively compared to the students in the courses with temporary employees. This might also be related to how much they engage in their own written reports. While one student group is given an allocated time to complete their report forms and hand them in during the lab hours; the other student group complete their reports in their own pace outside of the mandatory lab hours. This difference in how the written reports are completed might have an impact on the degree of reflection and learning outcome for the students. These findings further emphasize the importance of well-structured laboratory sessions with clearly communicated learning objectives as key to obtain the wanted learning outcomes for all STEM subjects with practical training. In conclusion, the use of permanent teaching assistants in laboratory teaching enhances the students' perceived learning in chemistry laboratory exercises and the present study further accentuates the need for motivated laboratory teaching assistants for the given feedback to be productive.
\end{abstract}

Keywords Learning Outcome, Practical Chemistry Laboratory, General Chemistry, Degree of Reflection

\section{Introduction}

Laboratory activities as an integral part of the teaching in technological and scientific subjects have played a key role in higher education for many decades [1], [2]. This type of teaching will by its nature be more resource intensive than one-to-many teaching, such as traditional lectures. It is natural that questions are raised concerning how useful this type of teaching is for the individual student's learning outcomes. In an education with ever-increasing demands for efficiency and resource utilization, the use of laboratory exercises in teaching science and technology is under pressure. Some have suggested that regular laboratory teaching can be replaced by software-based virtual laboratory exercises [3]. There still seems to be a consensus that some level of student-active laboratory teaching should be included when teaching technology and science subjects, focusing on developing higher order cognitive skills [4]. Laboratory activities have long played a distinctive and central role in the science curriculum and it is generally accepted that there are many benefits to engaging students in these types of activities. [1], [5]-[7]. More specifically research suggests that when properly developed, designed, and structured, laboratory-centred science curricula have the potential to enhance students' meaningful learning, conceptual understanding, and understanding of the nature of science. The laboratory as a platform for the development of learning skills is recognised around the world [7], [8].

Laboratory education provides a unique opportunity for students to practice their subject and apply theoretical concepts discussed in lectures. The chronological relationship between laboratory and lecture is critical to student knowledge synthesis [9]. In addition, having well 
thought out learning objectives that are clearly communicated, increases the likelihood of successfully completing them. [1]. Ideally educational practitioners should consider experiential learning theories [10], [11], and Bloom's Taxonomy [12] to clearly define the laboratory learning objectives of a laboratory. There is also some evidence that students themselves find practical work relatively useful and enjoyable when compared to other science teaching and learning activities. In a survey conducted among 1400 students in the United Kingdom [13], $71 \%$ chose 'doing an experiment in class' as one of the three methods of teaching and learning science they found 'most enjoyable'.

Investigating learning outcomes from laboratory teaching is important, as this learning environment has a different context than traditional classroom teaching. Laboratory teaching is often more interactive with individual feedback and ideally allows the student to reflect and find answers themselves from the data obtained. This differs from traditional lectures, where the theory or answer is merely given. This means that an effective teacher in the laboratory must use different teaching techniques compared to a classroom lecturer, and research has shown that laboratory staff is important for students' learning outcomes in laboratory courses [5]. With this background, it should be evident that practical laboratory work is crucial in teaching science and that optimized laboratory learning sessions is of outmost importance.

Chemistry teaching in higher education is an example of a topic within Science, Technology, Engineering and Math (STEM) where the balance between obtained learning outcomes and added costs is particularly relevant. This is because practical laboratory teaching needs to be in small groups due to Health and Safety requirements, which leads to a higher demand for instructors per academic credit in these courses. In addition, chemistry laboratory courses often require the use of expensive instruments and consumables, which further add to the costs of this type of teaching. It is therefore of general interest to evaluate how these learning elements add to the students learning.

On the 1st of January 2016, the Norwegian teaching institutions NTNU and the university colleges in Sør-Trøndelag, Ålesund and Gjøvik were merged into one. As two academic environments with overlap in material technology and chemistry were merged into one institute, differences in student learning and resource management became obvious. The former Institute of Chemistry and Materials Technology (IKMT) from the Sør-Trøndelag University College (HiST) and the Department of Materials Technology (IMT) from NTNU were combined into the new Department of Materials Science and Engineering (IMA).

Traditionally, NTNU employs PhD-students as teaching assistants in the laboratories. Permanent staff engineers are primarily used in research support and as facilitators before teaching starts and have little student contact. This contrasts with the practice of the university college where all laboratory teaching has traditionally been carried out by permanent staff engineers.

As shown in Table 1, the laboratory training in chemistry courses at the three-year engineering degree programs in Norway is conducted with permanent staff engineers who are also partly involved in giving feedback on reports from the lab exercises.

Table 1. Overview of academic resources used in laboratory teaching in General Chemistry at different universities/colleges that offer three-year education in Chemical Engineering in Norway

\begin{tabular}{|l|l|l|}
\hline University/College & Type of laboratory staff & Feedback on reports given by \\
\hline OsloMet & Engineers & Lecturer \\
\hline Østfold University College & Engineers/Lecturer & Lecturer \\
\hline $\begin{array}{l}\text { University of South-Eastern Norway } \\
\text { (Campus Porsgrun) }\end{array}$ & $\begin{array}{l}\text { Engineers (most of them with a master's } \\
\text { degree). }\end{array}$ & Engineers \\
\hline Western Norway University of Applied Science & Engineers & Lecturer/Engineers \\
\hline University of Stavanger & Engineers & $\begin{array}{l}\text { Engineers (Lecturer in masters } \\
\text { courses) }\end{array}$ \\
\hline
\end{tabular}


In the present paper we have looked at differences and similarities between laboratory courses in two similar introductory chemistry courses. We wanted to investigate how they are conducted and whether potential differences affect the students' perceived learning outcomes. In addition, we have examined how students make use of and assess the learning resources offered.

\section{Methodology}

The courses selected for comparison were TKJE1002 General Chemistry and TMT4115 General Chemistry. Both courses are taught in the first semester of their respective programs, and are of comparable size, both for lectures and lab course (Table 2 and 3 ). There is also a large degree of overlapping syllabus and similar tasks that are carried out in the lab, this is explained further below. Neither program has any formal requirements for chemistry from high school, so there will be a similar mix of students with and without experience of chemistry in both courses.

Table 2. Number of students who registered, attended and passed the exam, and number of students who passed the laboratory course in TMT4115 in 2013-2017

\begin{tabular}{|l|c|c|c|c|c|}
\hline & 2013 & 2014 & 2015 & 2016 & 2017 \\
\hline Registered for the exam & 131 & 114 & 130 & 130 & 115 \\
\hline Attended the exam & 118 & 105 & 121 & 127 & 112 \\
\hline Passed the exam & 113 & 97 & 110 & 117 & 93 \\
\hline $\begin{array}{l}\text { Passed the laboratory } \\
\text { course }\end{array}$ & 117 & 103 & 119 & 122 & 107 \\
\hline
\end{tabular}

Table 3. Number of students who registered, attended and passed the exam, and number of students who passed the laboratory course in TKJE1002 in 2013-2017

\begin{tabular}{|c|c|c|c|c|c|}
\hline & 2013 & 2014 & 2015 & 2016 & 2017 \\
\hline $\begin{array}{l}\text { Registered for the } \\
\text { exam }\end{array}$ & 152 & 161 & 172 & 142 & 149 \\
\hline Attended the exam & 150 & 154 & 162 & 133 & 138 \\
\hline Passed the exam & 139 & 134 & 149 & 114 & 122 \\
\hline $\begin{array}{l}\text { Passed the laboratory } \\
\text { course }\end{array}$ & 145 & 150 & 153 & 128 & 130 \\
\hline
\end{tabular}

The difference in the subjects is how the lab courses are taught. TKJE1002 uses the engineers to prepare everything before each task, teach in the laboratory and correct the reports afterwards. The engineers also help to improve the lab course over the years. TMT4115 uses engineers to prepare for the lab, while $\mathrm{PhD}$-students teach in the lab and approve the written reports after the lab.

TMT4115 General chemistry is taught for students in the master's program in industrial chemistry and biotechnology (five-year). The course is completed in the first semester with nine lab exercises, each of which has been allocated four hours in the lab. Before the students arrive at the laboratory, they must answer questions on preparation forms and have three questions related to HSE and three questions related to current theory approved. The time in the lab is used for a short summary and then performing the exercise with PhD-students present to supervise. All the exercises conclude with students filling in individual report forms that are submitted for approval before leaving the lab.

TKJE1002 General chemistry is taught for students at a bachelor's program (three-year) in chemical engineering, materials technology and bioengineering. The course is completed in the first semester, with eight exercises, each of which has been allocated two hours in the lab. The time in the lab is used for a short summary and then performing the exercise with engineers present to supervise. In the fall of 2017, parts of the course were conducted with a hired fellow due to a sick leave. For seven of the exercises, preparation forms are made available to the students in advance, with the expectation that the students use this to prepare for the lab on their own. Reports are written in pairs in the students' own time after completion of the lab. The focus is on theoretical understanding and it is therefore chosen to use the report form for six of the exercises in the first semester for the students. Nevertheless, two complete reports are written in the laboratory course, where feedback is given on the formal report demands as well as the theoretical content.

A survey was conducted in the spring of 2018 among students who had completed one of the two General Chemistry courses, TKJE1002 and TMT4115.

The survey was conducted using SelectSurvey [14]. This was chosen as it was a tool available through NTNU and gave us the option to tailor the survey to our needs. As mentioned, the questions were divided into three sections with 5-8 questions in each section. The answers were on a scale from "Completely agree" to "Completely disagree" (five levels), with the additional option "Don't know/not relevant".

Because the students taking TKJE1002 follow a mainly set course plan, we used the subjects in the later semesters to reach students who have completed the General Chemistry subject from several years (completed the course in 2015-2017). The survey was sent to these students by enlisting the help of lecturers in the later subjects and sending the survey by e-mail through the learning management system (LMS) Blackboard. In total the survey was sent to 259 students, and $52 \%$ replied to the entire survey.

For TMT4115 the course plan is not as set, so only the most recent group of students could be reached (completed in 2017). For these students the e-mail was sent using the General Chemistry subject's "room" on the Learning Management System used (Blackboard). This is a total of 107 students, and $38 \%$ replied to the entire survey.

A prize was promised for the student group with the highest percentage of answers compared to potential answers. This was divided by the subjects the students were 
contacted through. In hindsight, this favoured the students from TKJE1002 which were divided into more groups (6-7 different groups) than the students from TMT4115 (1 group).

The questions in the survey were divided into three topics that we felt were important to look at as part of the course. A section about students' perceived learning outcome in the lab course asked the students to assess how relevant different aspects of the lab were to the theory and to the exam. This was to get an overview of the relevance and usefulness of the overall lab courses.

The next section was about support during the scheduled lab course and concerned about the students' impression of the staff and their role during the scheduled lab. This was to see if the students have different experiences of the staff with the different approaches to teaching in the lab.

The last section was about support outside of the scheduled lab course. Again, this is to gauge the students' impression of the need for and quality of help outside of the scheduled time in the lab.

\section{Results and Discussion}

\subsection{Perceived Learning Outcomes}

The first part of the survey covered the students perceived learning outcome in the respective lab courses, including relevance for the exam, connection between theory and practice, and preparations before the lab exercises.

In general, the students in both subjects found the lab courses to be relevant for the theory and contributed to understanding, with $87 \%$ or more answering "Agree" or "Completely agree". The share of student answering "Completely agree" was higher for TKJE1002 (average $49 \%$ ) than for TMT4115 (average $26 \%$ ) for these two questions (Figure 1 and 2). This shows that the lab in both subjects are relevant to the curriculum and that the students find them useful in their learning.

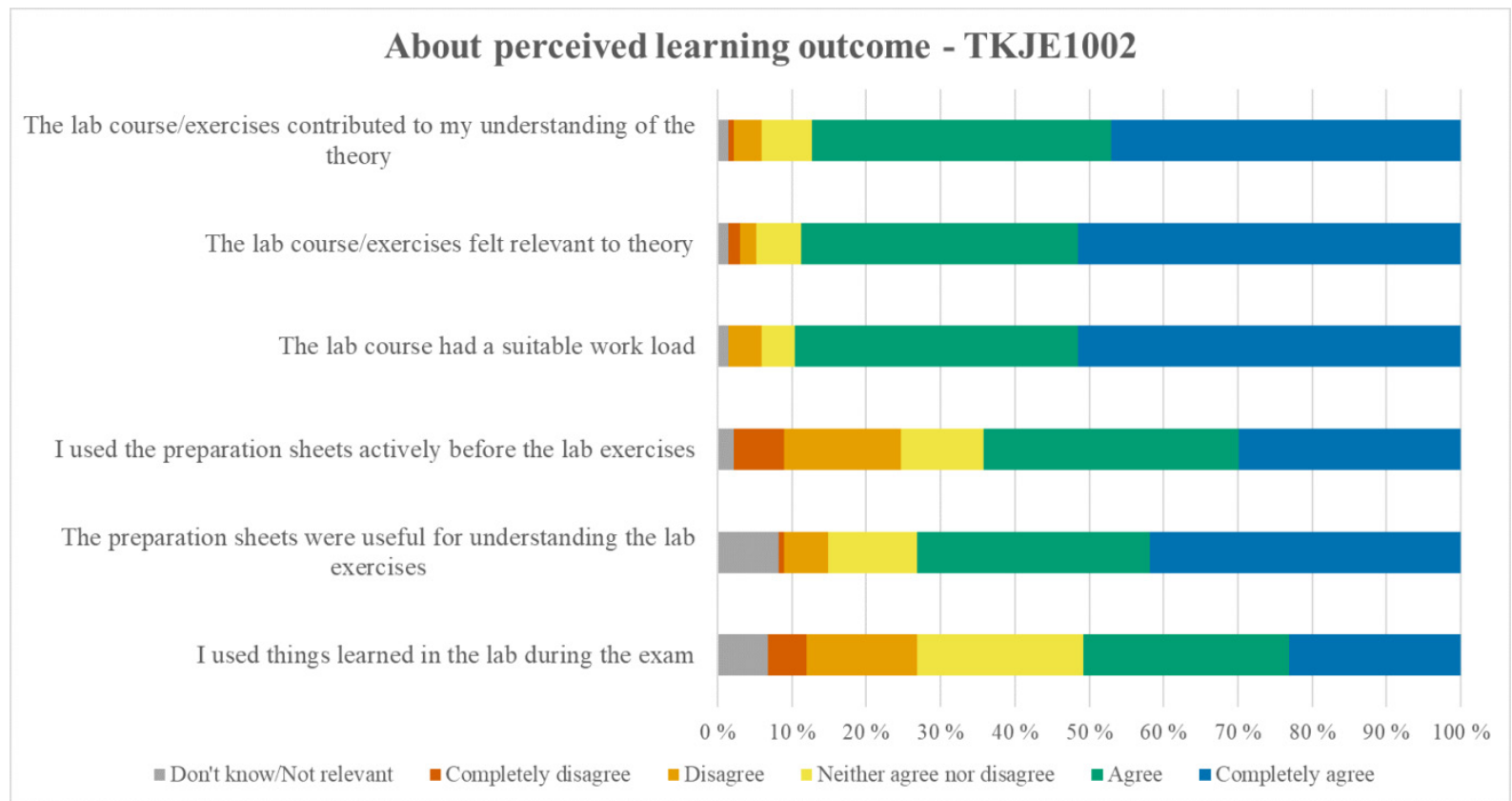

Figure 1. Results from survey covering perceived learning outcome for TMT4115 


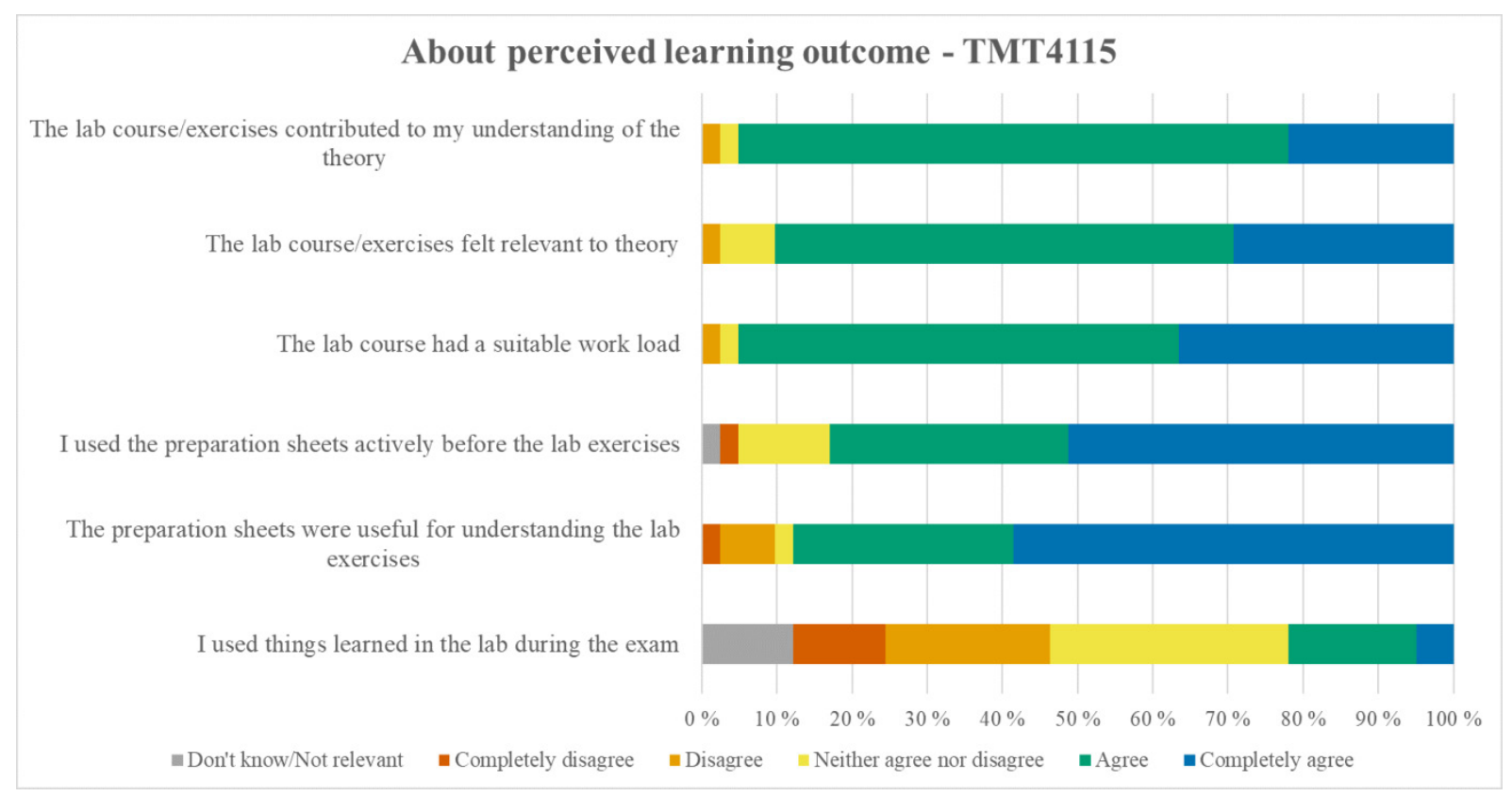

Figure 2. Results from survey covering perceived learning outcome for TMT4115

Both subjects use preparation forms that the students can use in order to actively prepare for each lab exercise. The results show that for TMT4115 $88 \%$ of the students agreed that the forms were useful as preparation before a lab exercise, and for TKJE1002 $73 \%$ agreed. Oddly enough, for both subjects more students find the forms useful than use them actively. This might indicate that even though some students didn't use the forms actively, they still see value in using them to prepare for an exercise, confirming that they are a valuable tool in learning.

When asked about how relevant the lab exercises are to the exam, there is a difference between the two subjects. $51 \%$ of the students in TKJE1002 said they were able to relate things learned in the lab to the exam, while only $22 \%$ of the students in TMT4115 said the same. This difference may have various causes. Questions set for the exam will naturally vary from year to year and a question that is directly related to a theme covered in exercises in the lab, can't necessarily be used in the same format every year. How a question is worded will also affect whether the students see the relevance to a lab exercise or not. Another possibility is that the lecturer in TKJE1002, in the more practical three-year engineering education, chooses to focus more on practical skills, and therefore relates the exam questions more to the practical work.

Another possible explanation for this difference may lie in the structure of the completion of the reports after a lab exercise. The students in TKJE1002 are expected to be more independent in their reflection on the syllabus covered in the lab exercises, with the writing of their reports outside the scheduled laboratory time. This might allow the students time to relate the lab work to the theory in a different way, and later see the connection between theoretical questions given in the exam and the lab more clearly.

\subsection{Support and Teaching Environment During Scheduled Lab}

The second part of the survey asked about support and the teaching environment during the scheduled lab course. This included the overall impression of the support available during the lab ("The staff were very helpful..."), and more specifically about perceived availability and preparedness of the teaching staff during the scheduled lab exercises.

For both subjects, the students' overall impression is that the teaching staff is very helpful during the scheduled lab exercises, with $86 \%$ and $85 \%$ in agreement in TKJE1002 and TMT4115 respectively (Figure 3 and 4). Similarly, a comparable share of students in both courses found the teaching staff to be well prepared in the lab, with $96 \%$ and $95 \%$ of students replying "agree" or "Completely agree" in TKJE10002 and TMT4115 respectively. The type of teaching staff seems to have little impact on the students' perceived quality of support given during the scheduled lab exercises. 


\section{Support and teaching environment during scheduled lab - TKJE1002}

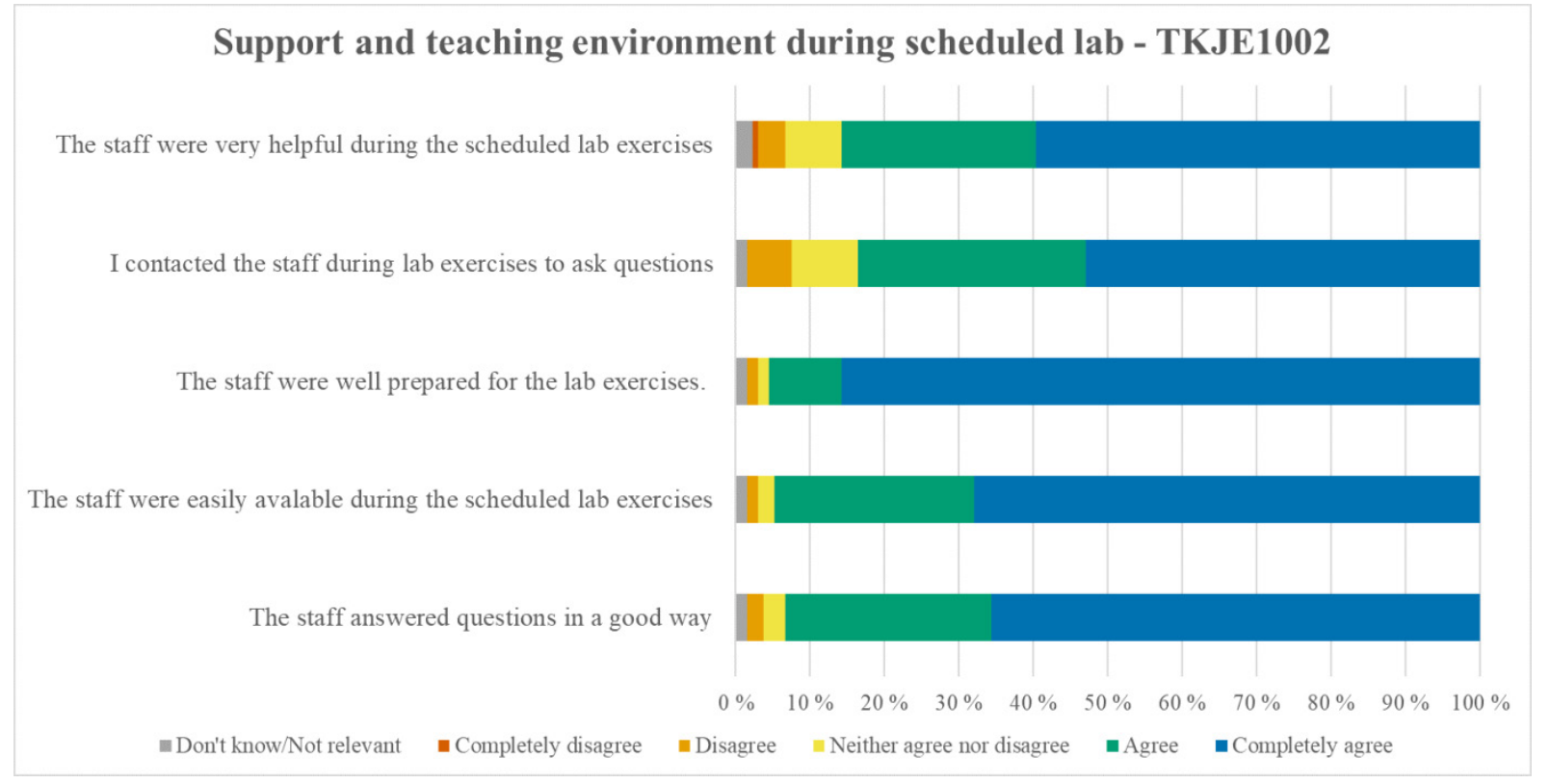

Figure 3. Results from survey covering support and teaching environment during scheduled lab for TKJE1002

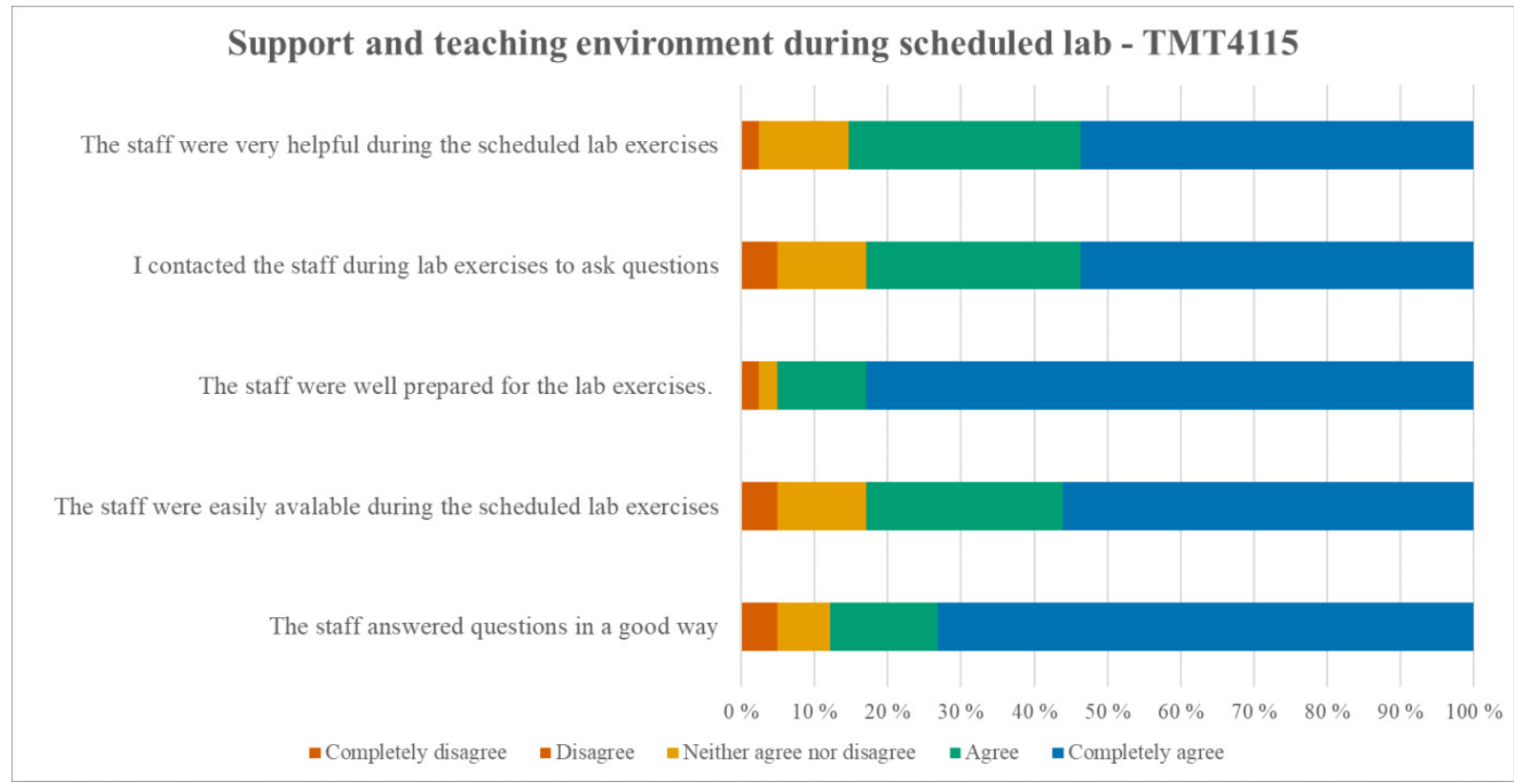

Figure 4. Results from survey covering support and teaching environment during scheduled lab for TMT4115

When asked more specifically about different aspects of help, there is a difference between the two subjects. The students in TKJE1002 are more in agreement when asked specifically about the availability of the staff $(95 \%)$ and their ability to give good answers to questions ( $94 \%$ ), than when asked in general about their helpfulness $(86 \%)$. For TMT4115, the students' answers to the specific types of support are comparable to the overall impression, with $88 \%$ and $85 \%$ in agreement when asked about ability to give good answers and their availability, respectively, and $85 \%$ finding the staff helpful.

The lab exercises are run with different load on the teaching staff. This may explain the difference in the students' perceived availability of the staff, as the single PhD-student teaching in the lab in TMT4115 will have more students to supervise compared to TKJE1002 where two permanent staff members supervise the same number of students. In addition, a PhD-student who does the teaching as part of their obligatory work duties might be less motivated as lab tutors than permanent teaching staff. Permanent staff who teach in the same course for consecutive years will also have the advantage of experience that is difficult to obtain for PhD-students who are only part of the course for a limited period. Another advantage of permanent staff is that the students will encounter the same personnel in multiple lab courses 
throughout their studies. This may make it easier for students to contact staff with questions.

\subsection{Support and teaching environment outside of scheduled lab}

Figure 5 and 6 show the replies to the last part of the survey, covering what the students' impressions of the availability and quality of support and feedback outside of the scheduled lab exercises.

The initial question establishes whether students chose to contact the staff outside of the scheduled lab exercises.
Only $22 \%$ of the students in TMT4115 answered that they chose to contact the staff. This may be because part of the scheduled lab exercises is time to complete the written report that needs to be handed in after the exercise, and that students use that time to ask questions that they may have brought to the staff otherwise. For TKJE1002 $44 \%$ of the students said they sought contact with the staff outside the lab exercise. These students write their report on their own time, which in turn means that if they have any questions while writing, they will need to contact the staff directly or by e-mail.

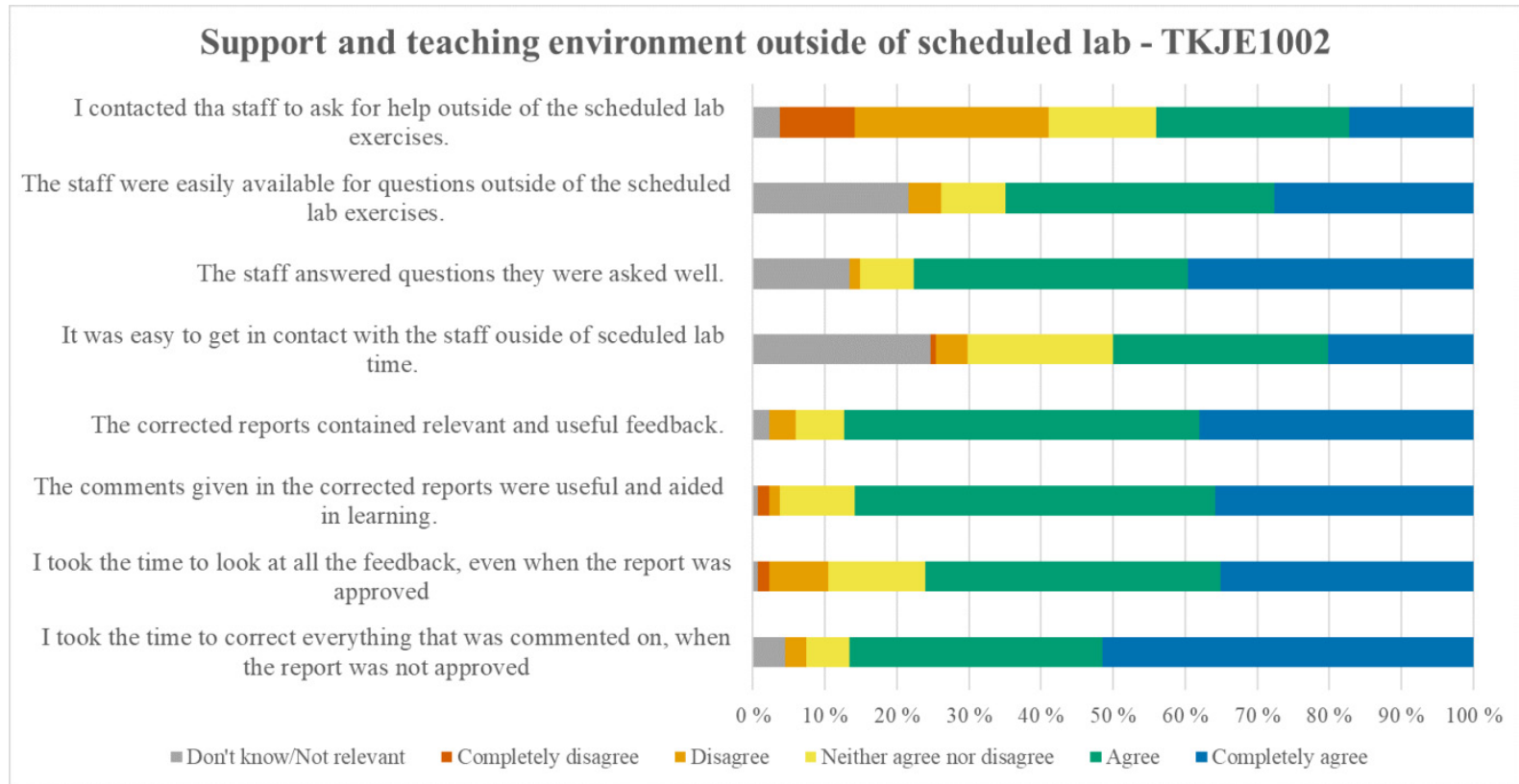

Figure 5. Results from survey covering support and teaching environment outside of scheduled lab for TKJE1002

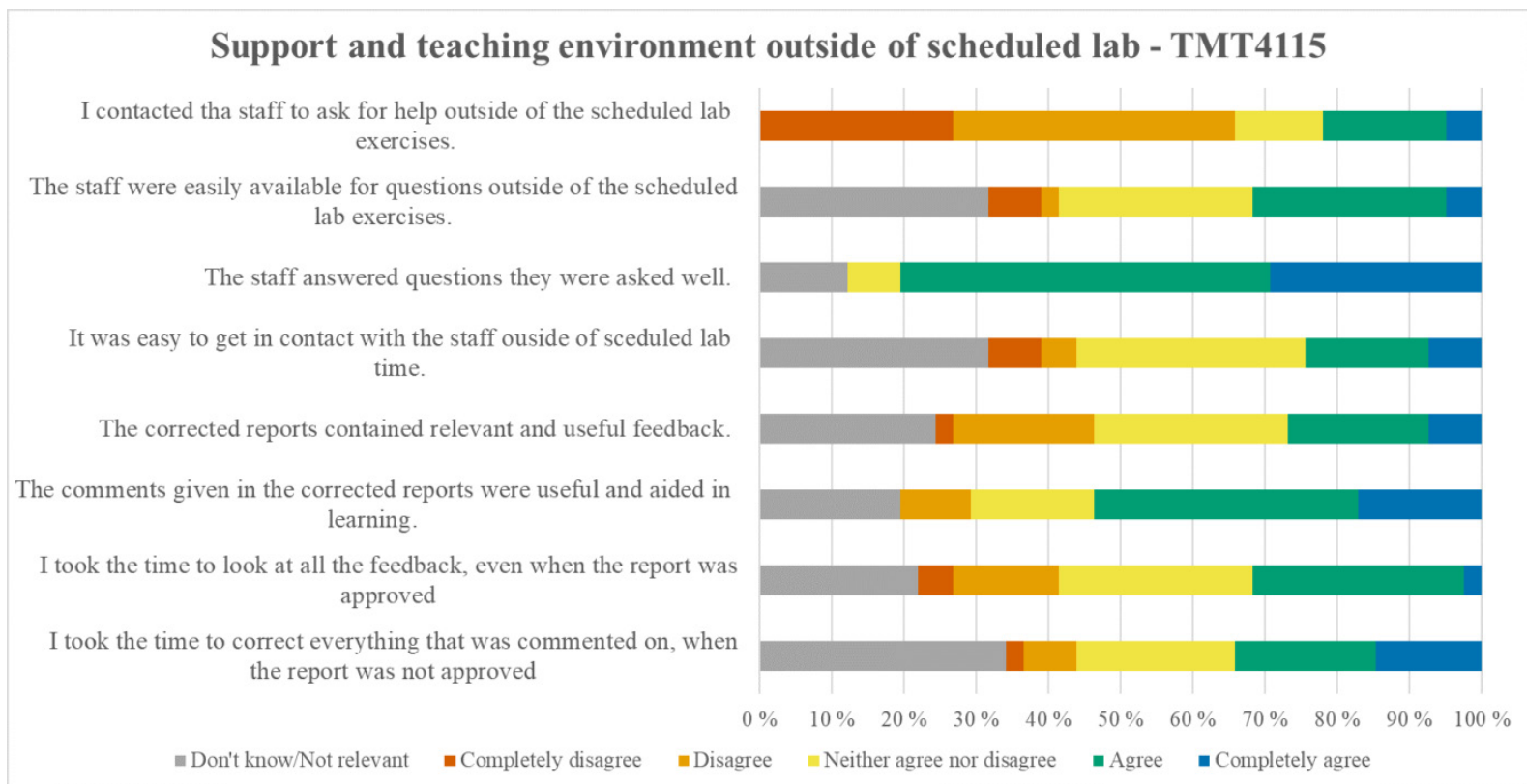

Figure 6. Results from survey covering support and teaching environment outside of scheduled lab for TMT4115 
When questioned about whether the students found the staff to be easily available, most students $(61 \%)$ in TMT4115 responded with "Not applicable/Don't know", which confirms that they didn't seek help outside the scheduled lab. This still leaves $39 \%$ of students who have an opinion on the availability of the staff, even though only $22 \%$ answered that they chose to contact staff. For TKJE1002 there is a similar trend, with $65 \%$ of students saying that the staff is easily available, even though only $44 \%$ chose to contact staff. Both results may be due to students accompanying other students to ask questions, therefore not actively seeking help but still perceiving that the staff are easily available.

In general, there is a difference in the replies between the student groups for these questions. The students from TKJE1002 chose to use the staff more actively and have a more positive impression of the availability of the staff, than the students in TMT4115. This may be due to that fact that both the scientific and technical staff in TKEJ1002 can be found in offices situated close to each other and close to where the students are working, making it easier to get in contact with them. This suggests the advantage of a shared space for lab and offices for technical and scientific staff, near where the students are working.

The last four questions relate to the feedback students receive on the written reports that they complete after each lab exercise. For TMT4115 on average $10 \%$ of students completely agree with the statements that they use the feedback actively and that the feedback is useful to them. It is important to note that on average $25 \%$ of the students have answered "Don't know/Not relevant" for these last four questions, indicating that they don't use the feedback at all. $31 \%$ of students say that they take the time to read though the feedback given on the report, even when it's approved. $54 \%$ of the students agree that the feedback is valuable and that they learned from it, and only $10 \%$ disagree.

For TKJE1002 a higher percent of students completely agree with the last four statements, with an average of $40 \%$. They think the corrected reports contain feedback that is relevant and valuable ( $87 \%$ agree or completely agree) and they take the time to look through the corrected reports, even when they have been approved ( $86 \%$ agree or completely agree).

This is where the biggest difference between these two courses can be seen, with on average $10 \%$ of students from TMT4115 answering "Completely Agree" compared to $40 \%$ from TKJE1002. This shows that the students in TKJE1002 use the feedback more actively and appreciate it in the lab exercise in their learning. Again, this might be related to how the reports are completed in the courses. The students in TKJE1002, who complete their reports more independently, may value the feedback higher since they have been given more time to reflect on their own learning. Completing the reports as part of the lab exercise with staff available negates some of the need for feedback and contact with staff later. The complete reports written after two of the exercises in TKJE1002 will also contain more valuable feedback for the students than the report forms.

It's worth noting that this difference in how the students write and hand in their reports may have an impact on the students' reflection on the theory related to the exercises and consequently on the learning outcomes. For TMT4115, the students are given an allocated time to complete their report forms and hand them in. This limits the time and degree of reflection possible for these students and allows them to "leave the work behind" once they leave the lab. In TKJE1002, on the other hand, students complete their reports at their own pace, which allows them to process and reflect to a much higher degree. In addition, writing complete reports for two of the exercises demands more understanding of the theory than merely completing a report form.

It's still important to note that though the feedback may be more time consuming than direct comments during writing, the students utilize these feedbacks actively in their learning. Previous surveys done among larger student groups have revealed that students feel that there is a lack of feedback on their own work during their studies. [12] Letting students complete their reports more independently will potentially allow for better learning outcome for the students.

As with most studies, the design of the current study is subject to limitations. The number of replies to our survey, especially from TMT4115 should ideally have been higher. Including students from several years of this subject, as we did with TKJE1002, could probably have given us a better basis for our data. The survey could also have been more comprehensive for some of the topics discussed. We find that more questions about the students' experience with the different teaching practices would have been relevant. However, we judged the length of the survey to be sufficient and wanted to limit the number of questions to reduce the risk of the students rushing through the end to finish the survey.

This is an early study mapping whether the students' note any differences between two similar lab courses and what implications these differences might have for their learning. More research is needed in order to advise with higher certainty how laboratory courses are run most effectively with concurrent optimized learning outcomes.

\section{Conclusions}

In conclusion we see that both lab courses are well suited to the theory that is taught, and the students feel that the lab exercises are relevant and contribute to their learning. The students are also happy with the staff and how the lab exercises are completed.

The greatest difference between the two courses is that the students in TKJE1002 achieve a closer relation to the 
staff from the start of their education. This makes it easier to seek contact later in the semesters. The students in TKJE1002 also use the feedback they are given on written reports more actively, creating a good foundation for further written work during their education. The most important findings in the present study is that students seem to reflect deeper on practical laboratory work when the teaching assistants are involved in all aspects of the lab-work and when writing complete laboratory reports.

On a more general note, it could be added that when practical work is used to enhance learning outcomes in STEM subjects, it is important that the learning objectives are clearly communicated. The present study also indicates that to include the laboratory staff in planning of the lab curriculum and lab report evaluation enhances the students perceived learning outcome of the laboratory training.

To further develop the understanding of the different ways students enhances their learning outcome and how they use productive feedback when doing practical work in different STEM subjects, more research in different institutional contexts is recommended.

\section{REFERENCES}

[1] A. Hofstein and V. N. Lunetta, "The laboratory in science education: Foundations for the twenty-first century," Sci. Educ., vol. 88, no. 1, pp. 28-54, Jan. 2004, doi: 10.1002/sc e.10106.

[2] A. Hofstein and V. N. Lunetta, "The Role of the Laboratory in Science Teaching: Neglected Aspects of Research," Rev. Educ. Res., vol. 52, no. 2, pp. 201-217, Jun. 1982, doi: 10.3102/00346543052002201.

[3] V. Potkonjak et al., "Virtual Laboratories for Education in Science, Technology, and Engineering: a Review," Comput. Educ., vol. 95, Feb. 2016, doi: 10.1016/j.compedu.2016.02 .002 .

[4] J. G. Quattrucci, "Problem-Based Approach to Teaching Advanced Chemistry Laboratories and Developing Students' Critical Thinking Skills," J. Chem. Educ., vol. 95, no. 2, pp. 259-266, 2018, doi: 10.1021/acs.jchemed.7b005 58 .

[5] R. Lazarowitz and P. Tamir, "Research on using laboratory instruction in science.," in Handbook of Research on Science Teaching and Learning Project, D. L. Gabel, Ed. Macmillan Publishing Company, Division of Macmillan, Inc, 1993.

[6] V. N. Lunetta, "The school science laboratory: Historical perspectives and contexts for contemporary teaching," in International Handbook of Science Education, B. Fraser and K. Tobin, Eds. Springer Netherlands, 1998.

[7] V. N. Lunetta, A. Hofstein, and M. P. Clough, "Learning and teaching in the school science laboratory: An analysis of research, theory, and practice.," in Handbook of Research on Science Education, S. K. Abell and N. G. Lederman, Eds. Routledge, 2013.
[8] A. Hofstein and P. M. Kind, "Learning In and From Science Laboratories," in Second International Handbook of Science Education, B. J. Fraser, K. Tobin, and C. J. McRobbie, Eds. Dordrecht: Springer Netherlands, 2012, pp. 189-207.

[9] L. D. Feisel and A. J. Rosa, "The Role of the Laboratory in Undergraduate Engineering Education," J. Eng. Educ., vol. 94, no. 1, pp. 121-130, 2005, doi: 10.1002/j.2168-9830.20 05.tb00833.x.

[10] D. A. Kolb, "Experiential learning: Experience as the source of learning and development," J. Organ. Behav., vol. 8, 1984, Accessed: Mar. 29, 2020. [Online]. Available: https://www.academia.edu/3432852/Experiential_learning _Experience_as_the_source_of_learning_and_developmen t.

[11] D. Boud and D. Walker, "Experience and Learning: Reflection at Work. EAE600 Adults Learning in the Workplace: Part A." Adult and Wokplace Education, Faculty of Education, Deakin University, Geelong, Victoria, Australia., 1991, Accessed: Mar. 29, 2020. [Online]. Available:https://www.academia.edu/29435057/Experienc e_and_Learning_Reflection_at_Work._EAE600_Adults_L earning_in_the_Workplace_Part_A.

[12] B. S. Bloom, "Taxonomy of Educational Objectives, Vol. 1." McKay, 1956, Accessed: Mar. 29, 2020. [Online]. Available: https://www.uky.edu/ rsand1/china2018/texts/ Bloom $\% 20$ et $\% 20$ al $\% 20$-Taxonomy $\% 20$ of $\% 20$ Educational $\% 20$ Objectives.pdf.

[13] B. Cerini, I. Murray, and M. J. Reiss, "Student Review of the Science Curriculum: Major Findings," 2003.

[14] "SelectSurvey," Feb. 26, 2019. https://selectsurvey.net/ (accessed Feb. 26, 2019). 